\title{
Intravaginal foreign body should be excluded in prepubertal cyclical vaginal bleeding without other evidence of precocious puberty
}

\author{
S.Upadrasta, L.Watson ${ }^{2}$, A.Natarajan', S.M.Ng ${ }^{1}$
}

1. Department of Paediatrics, Southport \& Ormskirk Hospitals NHS Trust, Ormskirk 2. Department of Paediatrics, Doncaster Royal Infirmary,

\section{BACKGROUND \& OBJECTIVES}

\section{BACKGROUND:}

- Isolated prepubertal menarche is described in the absence of other signs of precocious sexual development ${ }^{1}$ and is a self-limited condition ${ }^{2}$.

- This condition remains unclear in it's aetiology and there is currently no consensus on investigations to be undertaken.

\section{OBJECTIVES:}

To evaluate the following factors associated with persistent isolated cyclical vaginal bleeding:

- Clinical presentation

- Gonadotrophin-releasing hormone (GnRH) stimulation test

- Genital examination under anaesthetic (EUA)

- Pelvic ultrasound findings

\section{METHODS}

- Retrospective case series of 14 girls with isolated prepubertal menarche

- Data collection from 2 centres between January 2007 and December 2014

- All girls presented with persistent cyclical vaginal bleeding with no other signs of precocious puberty

\section{RESULTS}

\begin{tabular}{|l|c|c|}
\hline \multicolumn{3}{|c|}{ DEMOGRAPHICS } \\
\hline & Mean & Range \\
\hline Age (years) & 7.4 & 5.0 to 9.67 \\
\hline Height SDS & 0.33 & -1.02 to +1.68 \\
\hline Weight SDS & 1.01 & -0.74 to 2.76 \\
\hline BMI & 19.6 & 14.6 to 29.3 \\
\hline \\
-Vaginal bleeding was reported to be cyclical, ranging from \\
1 weekly to 3 monthly, lasting 1-4 days in duration. \\
-Bleeding persisted between 6 to 18 months in all girls \\
-Pelvic ultrasound showed prepubertal uterus with no \\
identifiable endometrial echo in all girls
\end{tabular}

\begin{tabular}{l|c|c|}
\hline \multicolumn{3}{|c|}{ GnRH STIMULATION TEST } \\
\hline & Mean & Range \\
\hline LH peak (U/I) & 3.1 & $0.3-14$ \\
\hline $\begin{array}{l}\text { Peak LH/FSH } \\
\text { Ratio }\end{array}$ & 0.23 & $0.07-0.66$ \\
- Oestradiol levels were < $100 \mathrm{pmol} / \mathrm{l}$ in all girls \\
-Bone age showed no advancement in all girls \\
-EUA was normal in 7 out of 8 girls. \\
-One girl was found to have $1.5 \mathrm{~cm}$ foreign body; she \\
presented with cyclical vaginal spotting weekly for 6 \\
months prior to EUA
\end{tabular}

\section{CONCLUSIONS}

- Baseline LH, FSH, oestradiol, adrenal androgens, GnRH stimulation test, pelvic ultrasound for endometrial echo and bone age following clinical evaluation should be performed in prepubertal girls presenting with persistent and cyclical vaginal bleeding, in order to exclude precocious puberty.

- EUA should be considered in persistent isolated cyclical vaginal bleeding to exclude other causes such as intravaginal foreign body

\section{REFERENCES:}

1. Shanthi M. Pinto, Anne S. Garden. American Journal of Obstetrics and Gynaecology 2006; 195: 327-329

2. Aikaterini A.Nella, Paul B.Kaplowitz, Mary Scott Ramnitz, Radha Nandagopal. Journal of Pediatric Endocrinology and metabolism 2014; 27(9-10): 821-825 